Article

\title{
Correlation between Bone Turnover Markers and Bone Mineral Density in Patients Undergoing Long-Term Anti-Osteoporosis Treatment: A Systematic Review and Meta-Analysis
}

\author{
Lingyun Hong ${ }^{1,2,+}$, Dan Liu ${ }^{2,+}$, Feng Wu ${ }^{2,3}$, Meiqi Wang ${ }^{1,2}$, Yu Cen ${ }^{2}$ and Lan Ma ${ }^{2,4, *(D)}$ \\ 1 Department of Chemistry, Tsinghua University, Beijing 100084, China; lightich0929@163.com (L.H.); \\ wangmq1996@163.com (M.W.) \\ 2 A Division of Life Science and Health, Tsinghua Shenzhen International Graduate School, Tsinghua \\ University, Shenzhen 518055, China; danieliu091@aliyun.com (D.L.); wu8721@126.com (F.W.); \\ cenyu427@126.com (Y.C.) \\ 3 School of Life Sciences, Tsinghua University, Beijing 100084, China \\ 4 Tsinghua-Berkeley Shenzhen Institute (TBSI), Tsinghua University, Shenzhen 518055, China \\ * Correspondence: malan@sz.tsinghua.edu.cn; Tel.: +86-755-26033033 \\ $+\quad$ They are co-first authors.
}

Received: 19 December 2019; Accepted: 18 January 2020; Published: 24 January 2020

Featured Application: This article was conducted to systematically analyze the correlation between BTMs and BMD and identify potential BTMs that show promising correlations with BMD changes in patients treated for osteoporosis, providing a clinical reference for the physicians in evaluating the long-term effect of the intervention on BMD changes and further on the future risk of fragility fracture.

\begin{abstract}
This systematic review and meta-analysis aimed to evaluate the correlations between the bone turnover markers (BTMs) and the bone mineral density (BMD) in patients treated for primary osteoporosis and to identify promising BTMs for the prediction of future BMD changes. The PubMed, EMBASE, Cochrane Library, and Web of Science databases were searched for relevant studies that investigated the relationship between the BTMs and the BMD changes in patients treated for osteoporosis. All significant correlation coefficients of the baseline BTMs or changes in BTMs from baseline with the BMD changes from baseline under different interventions from eligible studies were used for systematic review and the subgroup analyses. The correlations were analyzed in terms of bone sites, intervention, time duration of BTMs measurements, and time duration of BMD measurements. Twenty-two records reporting correlation coefficients and the corresponding $p$-values were included, 13 of which were enrolled in the further subgroup analyses. The combined results from the systematic review and meta-analyses indicated that the changes in osteocalcin (OC), procollagen type I N propeptide (PINP), and urine $\mathrm{N}$-terminal crosslinking telopeptide of type I collagen (U-NTX), or the PINP at baseline tended to be useful in evaluating the long-term BMD changes after drug intervention.
\end{abstract}

Keywords: bone turnover markers; bone mineral density; correlation; osteoporosis; systematic review and meta-analysis

\section{Introduction}

Osteoporosis is a systemic skeletal disorder that is characterized by low bone mass, decreased bone strength, and the microarchitectural deterioration of bone tissue. Osteoporosis often develops 
asymptomatically, and it is generally found at a first occurrence of fragility fracture. Due to the serious consequences of osteoporosis, fractures often cause a heavy economic burden, severely impact patients' quality of life, and increase disability and mortality, especially when a fracture occurs at the hip [1].

Clinical therapies for the treatment of primary osteoporosis (i.e., menopause- and aging-related osteoporosis) are mainly classified as antiresorptive and anabolic. The anti-osteoporosis drugs approved by the United States Food and Drug Administration (FDA) include bisphosphonates (BPs) (i.e., alendronate, risedronate, ibandronate, and zoledronic acid, etc.), hormone replacement therapy (HRT), raloxifene, denosumab, and calcitonin as antiresorptive, and teriparatide as anabolic [2].

Decreasing the risk of fracture and prevention of future fragility fractures are the primary goals for the clinical treatment of osteoporosis. Therefore, the prediction of fracture risk is an important subject and worthy of in-depth research. The relationship between bone mineral density (BMD) measurement and fracture risk has been clearly established, and BMD remains the best test for assessing fracture risk. However, BMD (bone mineral density) cannot identify individuals who will develop a fracture in the future [3]. Due to a general overlap in the bone densities of patients who tend to develop a fracture and those who do not, a high ratio of bone turnover over time has been considered an additional factor that contributes to future fracture [4]. Bone turnover markers (BTMs) are a series of proteins and peptides that are released during the metabolic process of bone remodeling and include markers of bone formation and bone resorption [5]. They provide a noninvasive approach for studying bone turnover and are easily and precisely measured, especially by automated analyzers. In most studies, high levels of BTMs were associated with an increased fracture risk of spine and hip in women $[3,4,6]$.

Clinically, BTMs and BMD are independent predictors of fracture risk for clinicians. However, fracture risk increases with the combined consideration of alterations in both factors rather than each factor individually. Nevertheless, BTMs seem a better choice for physicians in the monitoring of early responses to anti-osteoporosis therapy because of the delayed response of BMD to clinical treatment. Since both predictors are independent and essential, many researchers studied the relationship between the changes in biochemical bone markers and BMD in treated and untreated osteoporotic patients to evaluate the value of bone markers in predicting long-term BMD changes. However, the results of these studies are sometimes controversial and generally exhibit significant disparity across studies. The present study performed a systematic review and meta-analysis on the correlations between clinically used markers of bone turnover and BMD at various bone sites in patients treated for osteoporosis to examine the potential use of biochemical markers of bone turnover in predicting long-term treated BMD changes and to identify some promising biochemical markers.

\section{Materials and Methods}

This systematic review and meta-analysis was conducted following the Preferred Reporting Items for Systematic Reviews and Meta-Analysis (PRISMA) statement [7].

\subsection{Search Strategy}

The PubMed, EMBASE, Cochrane Library, and Web of Science databases were searched from inception through March 2018 using the combination of following key words: bone mineral density/bone mass, biochemical marker of bone turnover, osteoporosis, anti-osteoporosis therapy, and/or fracture. During the search process, each keyword was searched using all of its synonyms or subitems, if they existed. For example, when we searched for "osteoporosis"-related items, "osteoporosis", "primary osteoporosis", "postmenopausal osteoporosis", "postmenopausal osteoporosis [MeSH Terms]", "osteoporosis [MeSH Terms]", "OP", and "PMO" were also included. We manually searched the corresponding references linked to relevant reviews and manually updated our search results for the latest research relevant to our subject during the whole process of this systematic review. The detailed search strategy is provided in online Supplementary Data 1. 


\subsection{Eligibility and Exclusion Criteria}

Two reviewers (L.Y.H. and D.L.) examined each study, and discrepancies were resolved through further discussion (L.Y.H., D.L., and F.W.). Studies were eligible for inclusion if they met the following criteria: (1) controlled clinical trials or observational studies, except extension studies; (2) correlation coefficients with p-values between biochemical markers of bone turnover and BMD were reported as effect size; and (3) patients enrolled and treated for primary osteoporosis. Studies were excluded if they were (1) irrelevant studies; (2) reviews; case reports, abstracts, or letters to editor; (3) animal models or cell lines as research subject; (4) female patients with unnatural menopause caused by ovariectomy or ovariohysterectomy; or (5) patients with a history of any illness affecting bone and mineral metabolism or pretreated with any medications known to affect bone metabolism.

\subsection{Data Abstraction}

The characteristics of eligible studies, the characteristics of the included outcomes, and the correlation coefficients with corresponding p-values were extracted from the eligible studies. The characteristics of the eligible studies included study, age, sex, sample size, ethnicity/region, study design, fasting, intervention, treatment duration, and supplementation. The characteristics of the outcomes included bone markers, bone markers assessments, BMD measurements time points, and BMD measurements. All of the above data were independently extracted by L.Y.H. and D.L.

\subsection{Quality Assessment and Potential Bias}

All of the enrolled RCTs were evaluated for the risk of bias according to the following six aspects [8]: random sequence generation, allocation concealment, blinding of participants and personnel, blinding of outcome assessment, incomplete outcome data, and selective reporting. Each item was assessed as low risk, unclear risk, or high risk.

Similarly, the risk of bias of all the enrolled nonrandomized studies were evaluated using a tool of ROBINs (i.e. Risk of Bias In Non-randomized Studies of Interventions) according to following items [9]: representativeness of study patients, assessment of outcome, whether follow-up duration was sufficient for outcomes to occur, adequacy of follow-up, and source of study funding. Each item was assessed as low risk, unclear risk, or high risk, except for the source of study funding, which was assessed as for profit, not for profit, or not reported. The quality assessment results of RCTs and nonrandomized studies were gathered in the risk of bias tables.

\subsection{Statistical Analysis}

Subgroup analyses were performed to calculate the summary correlations by group of bone sites (femoral neck, lumbar spine, total hip, trochanter, and total body), intervention, time duration of the BTMs measurements, and time duration of the BMD measurements in patients treated for osteoporosis. We use the correlation coefficient itself as the effect size. All the original correlation coefficients were transformed by using a Fisher' z-transformation; after the analysis, the summary value of Fisher's z was back-transformed into the summary correlation coefficient $r$ (COR) with a corresponding 95\% CI (i.e., confidence interval) [10]. All the subgroup analyses were calculated by groups of different time points of the measurements of the biochemical markers. Considering the different mechanisms behind various therapies for osteoporotic patients, we first classified the included drugs into groups of the antiresorptive therapy or anabolic therapy according to their primary effects on bone turnover; then, we conducted these subgroup analyses under antiresorptive therapy and anabolic therapy, respectively. The heterogeneity of the studies was estimated by Cochran's $Q$ test and Higgin's I2 statistic. The effect model was determined according to the specific situation that a fixed model is suitable with regard to the nonsignificant heterogeneity ( $p>0.1$ and $\left.\mathrm{I}^{2}<50 \%\right)$; otherwise, a random-effect model should be used [11]. All the calculating process of meta-analyses were performed by using RStudio software (Version 1.1.456, Rstudio, Inc., Boston, MA, USA). All the significant correlation coefficients between the BTMs and BMD 
changes and the collected results of subgroup analyses were plotted by using MATLAB (MATLAB and Statistics Toolbox Release 2018a, The MathWorks, Inc., Natick, MA, USA). In addition, the correlation coefficient values were defined as follows: very strong correlation $(\geq 0.8)$, moderately strong correlation $(0.4-0.8)$, and poor correlation $(\leq 0.4)$. $p$-values lower than 0.05 were considered statistically significant. In this study, only the candidates with an absolute correlation higher than 0.4 were considered meaningful.

\section{Results}

\subsection{Search Results}

A total of 21,166 records were identified through the literature search. After the removal of 8042 duplicates, 12,764 papers remained, and 10,191 articles underwent further exclusion based on the titles and abstracts. The remaining 859 articles underwent full-text screening, and another 837 studies were excluded. Among the excluded 837 records, nine records were reviews, 803 records did not report the outcome of interest, 11 records had major deficiencies on the study design in terms of the enrolled patients and the measurements of the BTMs, and another 14 records were extension studies. Finally, 22 records were eligible for this systematic review, among which 13 records were included in the further meta-analysis. A flow chart of the literature search and study selection process is presented in Figure 1.

\subsection{Study Characteristics}

The characteristics of the eligible studies were given in Table 1, and the characteristics of the outcomes in eligible studies are given in Supplementary Data 2 (Table S1).

A total of 6666 osteoporotic patients from various countries such as China, America, Japan, Denmark, Finland, Italy, Australia, England, and Korea were recruited, and their average ages ranged from 50 to 74 years. Of the 22 eligible studies, 20 studies were performed on females, one study was performed on males, and the remaining one study was performed on both sexes. Twelve randomized controlled trials and 10 nonrandomized trials were included. Whether patients underwent fasting before sample collection was reported in 20 studies, with the remaining two not reporting such details. Drugs used for the intervention group included alendronate, ibandronate, risedronate, calcitonin, denosumab, HRT, raloxifene, and teriparatide. The assessments of BTMs varied across the different studies, among which bone alkaline phosphatase (ALP) was assessed by immunoassay (IA), ELISA, or immunoradiometric assay (IRMA); osteocalcin (OC) was assessed by ELISA, IA, IRMA, HPLC, or radioimmunoassay (RIA); procollagen type I N propeptide (PINP) was assessed by IA or RIA; procollagen type I C propeptide (PICP) was assessed by RIA; tartrate-resistant acid phosphatase $5 b$ (TRACP-5b) was assessed by ELISA or IA; serum C-terminal crosslinking telopeptide of type I collagen (S-CTX), urine CTX serum C-terminal crosslinking telopeptide of type I collagen (U-CTX), and urine N-terminal crosslinking telopeptide of type I collagen (U-NTX) were assessed by ELISA, electrochemiluminescence (ECL), or IA; deoxypyridinoline (DPD) was assessed by HPLC, IA, or ELISA; and pyridinoline (PYD) was assessed by HPLC. BMD was tested at different sites (mainly femoral neck, lumbar spine, total hip, total body, and trochanter) all by dual energy X-ray absorptiometry (DXA), except in one study that used dual photon absorptiometry (DPA).

\subsection{Quality Assessment of the Eligible Studies}

The quality assessment results of the random controlled trials and nonrandom trials are presented in Figure 2. Among the 12 RCTs (Figure 2a), two studies were evaluated as high risk, and three studies were evaluated as unclear risk, with the remaining seven studies evaluated as low risk. Four of the 10 nonrandomized trials were assessed as high risk, four studies were evaluated as unclear risk, and the remaining two were evaluated as low risk (Figure 2b). 


\subsection{Findings from the Systematic Review}

\subsubsection{Pretreatment BTMs and BMD Changes after Drug Intervention}

The statistically significant correlations between the baseline BTMs and the BMD changes are shown in Figure 3. In a placebo-controlled, randomized clinical trial, pretreatment bone ALP was moderately and positively associated with the lumbar spine BMD changes after 12-month teriparatide intervention $(r=0.43, p<0.01)$ [12] (Figure 3a). Baseline PINP was positively and moderately associated with changes in lumbar spine BMD at 12 and 18 months under teriparatide intervention $(r=0.5$ at 12 months, $p<0.01 ; r=0.41$ at 18 months, $p<0.05$ ) [12].

Kim et al. showed that the pretreatment U-NTX positively and moderately correlated with the femoral neck BMD changes after 12 months of HRT treatment $(r=0.451, p<0.001)$ [13]. Chen et al. showed that the correlation of U-NTX at baseline was also positive and moderate with lumbar spine BMD changes after 18 months of teriparatide intervention $(r=0.4, p<0.05)$ [14] (Figure 3b).

\subsubsection{Changes in Markers of Bone Formation and Changes in BMD after Drug Intervention}

In the study conducted under the combination intervention of $10 \mathrm{mg} / \mathrm{d}$ alendronate and HRT, the changes of the bone ALP levels between baseline and the sixth month after drug initiation were negatively and moderately associated with the total hip or trochanter BMD changes from baseline to the $36^{\text {th }}$ month $(r=-0.607$ at total hip, $p<0.001 ; r=-0.523$ at trochanter, $p<0.001)$, as were the correlations under the $10 \mathrm{mg} / \mathrm{d}$ alendronate intervention alone $(r=-0.411, p<0.001)$ [15] (Figure 4a).

Ravn et al. showed the changes of serum OC levels between baseline and the $12^{\text {th }}$ month correlated moderately and negatively with spine, total body, and hip BMD changes after 48 months of $5 \mathrm{mg} / \mathrm{d}$ alendronate intervention ( $r=-0.63$ at spine, $p<0.001 ; r=-0.49$ at total body, $p<0.001 ; r=-0.42$ at hip, $p<0.001$ ) [16] (Figure 4b).

The six-month changes of PINP from baseline were negatively and moderately correlated with lumbar spine or total hip BMD changes after 36 months of denosumab intervention $(r=-0.42$ at lumbar spine, $p<0.001 ; r=-0.47$ at total hip, $p<0.001$ ) [17] (Figure 4c). In several studies, the changes of PICP after drug initiation were poorly associated with the BMD changes in patients under the anti-osteoporosis therapy, and their absolute correlation values were lower than 0.3 [14] (Figure 4d).

\subsubsection{Changes in Markers of Bone Resorption and Changes in BMD after Drug Intervention}

Kim et al. and Ravn et al. also showed that the sixth and $12^{\text {th }}$ month U-NTX changes from baseline were negatively and moderately associated with hip, total body, and spine BMD changes after 48 months of treatment with $5 \mathrm{mg} / \mathrm{d}$ alendronate ( $r$ between -0.63 and $-0.49, p<0.001$ ) $[13,16]$ (Figure $5 \mathrm{a}$ ).

In the study conducted by Ravn et al., under the $5 \mathrm{mg} / \mathrm{d}$ alendronate intervention, the six and 12-month U-CTX changes from baseline were moderately and negatively associated with the spine, hip, and total body BMD changes after 48 months of drug initiation $(r=-0.49$ to $-0.67, p<0.001)$ [16] (Figure $5 b$ ). Eastell et al. showed that the serum CTX changes between baseline and the sixth month were also negatively and moderately correlated with the total hip BMD changes after 36 months of denosumab treatment $(r=-0.44, p<0.001)$ [17] (Figure 5c). In a study conducted by Okabe et al., the changes of urine DPD levels between baseline and the third or sixth month were moderately and negatively associated with lumbar spine BMD changes after six months of HRT intervention $(r=-0.547$ after three months, $p<0.01 ; r=-0.535$ after six months, $p<0.05$ ) [18].

In several studies, the changes of serum NTX and TRACP5b after drug initiation were poorly associated with the BMD changes in patients under the anti-osteoporosis therapy, and their absolute correlation values were lower than $0.3[19,20]$. No helpful information was found from the limited data of the correlations between urine PYD/HPR and BMD changes. 


\subsection{Findings from the Subgroup Analyses}

All data of the subgroup analyses results are collected in Supplementary Data 2 (Tables S2-S5). All the original forests of the subgroup analyses are shown in Supplementary Data 3.

The correlations between the baseline BTMs and BMD changes underwent a subgroup analysis by a group of BTMs. According to the results of the subgroup analyses, we found that the baseline procollagen type I $\mathrm{N}$ propeptide (PINP) values were moderately and positively correlated with the BMD changes (COR PINP $=0.42,95 \%$ CI: $0.34-0.50$, heterogeneity: $\mathrm{I}^{2}=0 \%, p=0.4$ ), while the correlations between other BTMs and BMD changes were lower than 0.4, indicating that the other baseline BTMs and the BMD changes were poorly correlated.

The results of the subgroup analyses on the correlation between the changes in BTMs and BMD were collected in Figure 6 and grouped by bone sites, intervention, the time duration of BTMs measurements, and the time duration of BMD measurements, respectively. Figure 6a shows the results of subgroup analyses by a group of bone sites, in which the biomarker of U-NTX was moderately correlated with total body BMD changes (COR $=-0.44,95 \% \mathrm{CI}:-0.58$ to -0.29 ; heterogeneity: $\mathrm{I}^{2}=43 \%$, $p=0.18$ ). Figure $6 \mathrm{~b}$ showed the subgroup results by group of intervention. In Figure $6 \mathrm{~b}$, the changes in PINP and BMD under denosumab intervention were moderately correlated $(\mathrm{COR}=-0.44,95 \% \mathrm{CI}$ : -0.57 to -0.31 ; heterogeneity: $\mathrm{I}^{2}=0 \%, p=0.71$ ). Figure $6 \mathrm{c}$ presented the results of subgroup analyses grouped according to the time duration of BTMs measurement, from which we could conclude that the changes of OC and UNTX from baseline to the $12^{\text {th }}$ month after drug intervention were moderately associated with the BMD changes (COR $\mathrm{OC}=-0.46,95 \% \mathrm{CI}:-0.59$ to -0.30 , heterogeneity: $\mathrm{I}^{2}=0 \%$, $p=0.73 ; \mathrm{COR}_{\mathrm{UNTX}}=-0.43,95 \% \mathrm{CI}:-0.61$ to -0.21 , heterogeneity: $\mathrm{I}^{2}=57 \%, p=0.13$, respectively). Finally, Figure $6 \mathrm{~d}$ showed the results of subgroup analyses grouped according to the time duration of the BMD measurement; in Figure 6d, we could see that the changes of U-NTX were moderately correlated with the BMD changes from baseline to the $48^{\text {th }}$ month after drug initiation (COR $=-0.52$, $95 \%$ CI: -0.64 to -0.21 , heterogeneity: $\mathrm{I}^{2}=0 \%, p=0.82$ ).

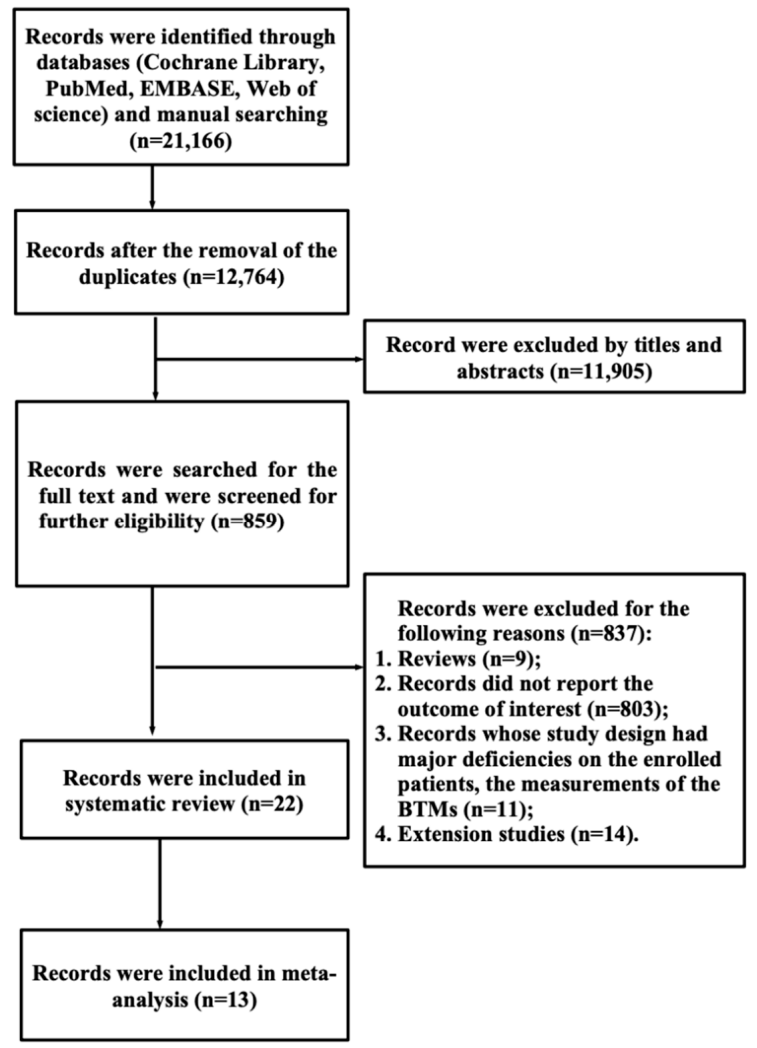

Figure 1. Flow chart of the literature search and study selection. 


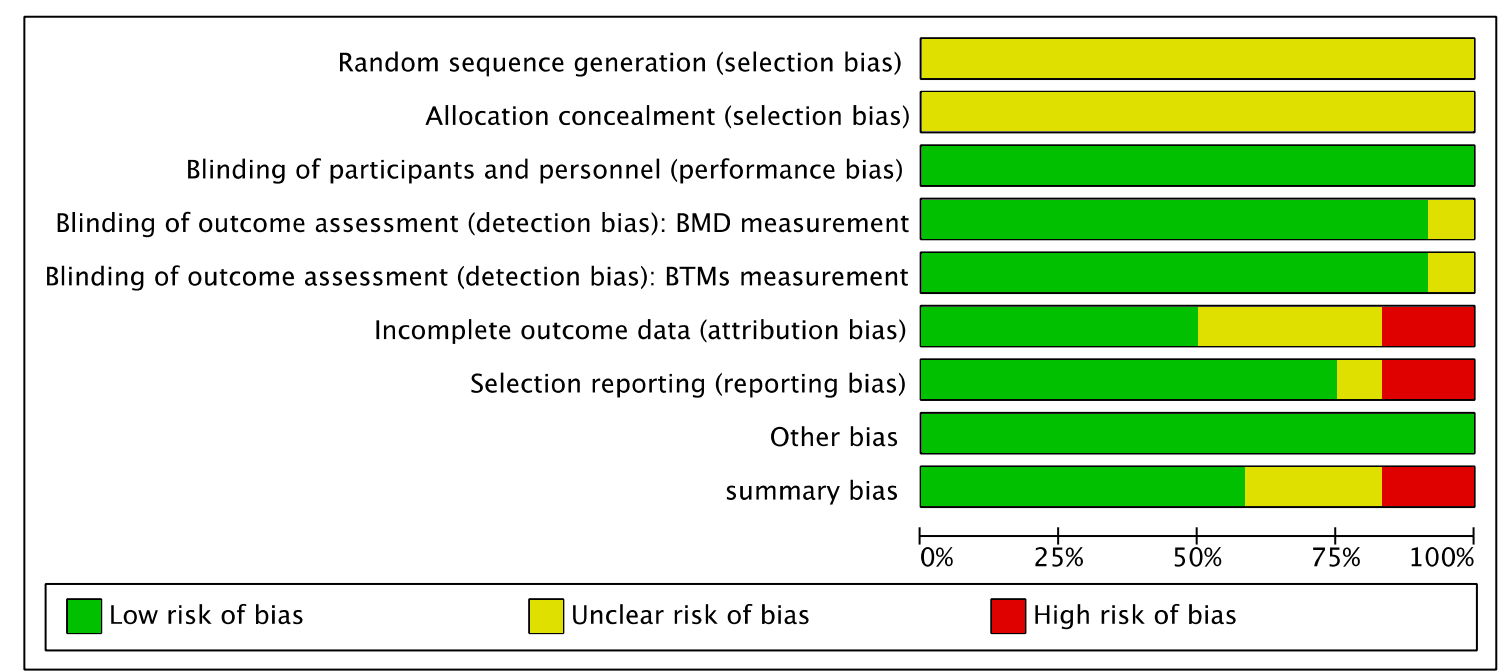

(a)

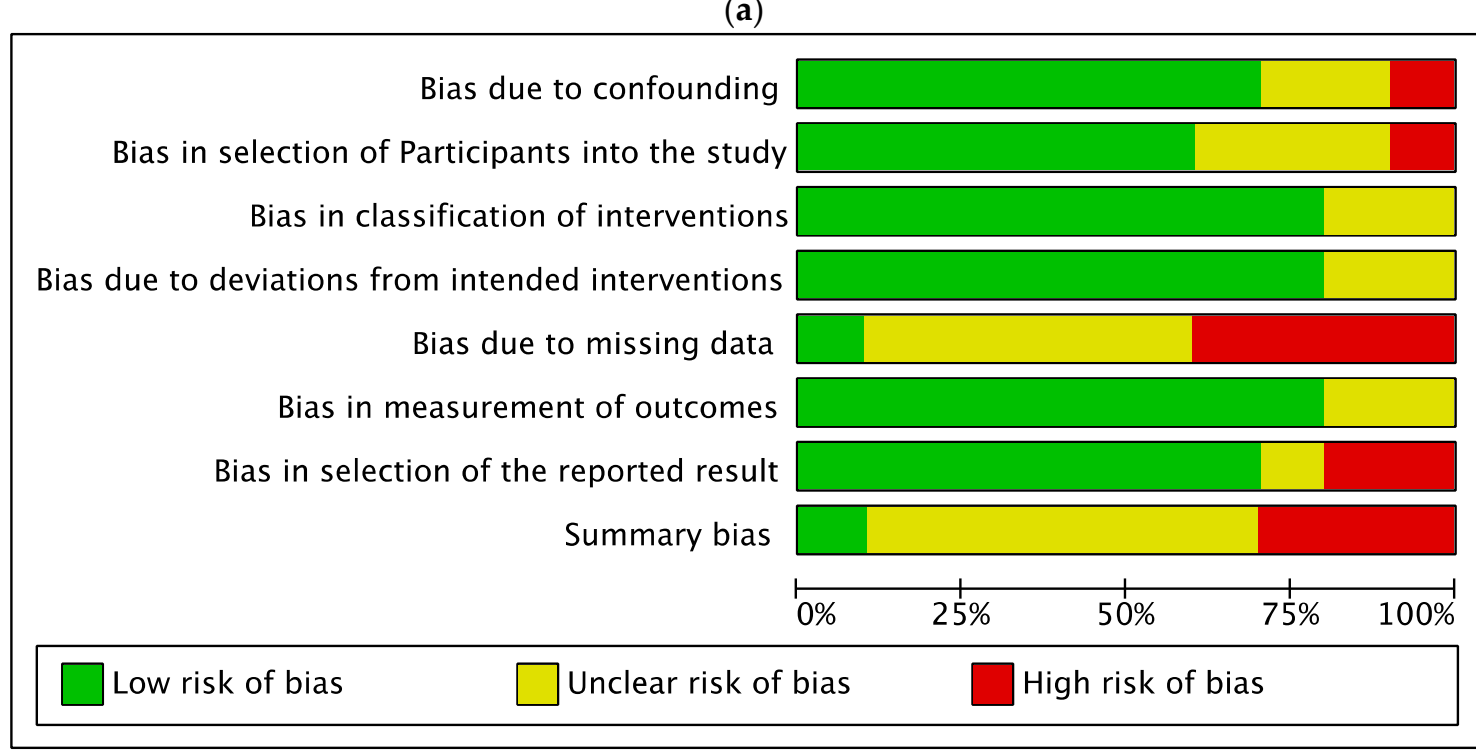

(b)

Figure 2. Quality assessment of the eligible studies. (a) Summary of the quality of the randomized controlled trials; (b) Summary of the quality of the nonrandomized trials.
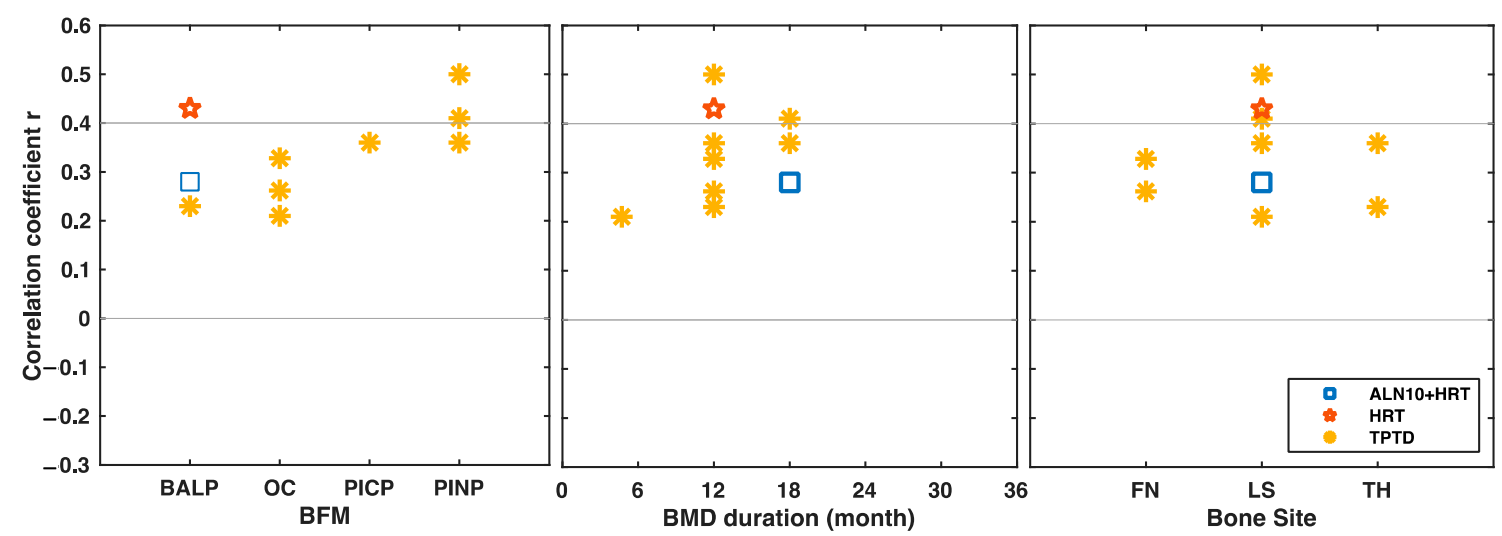

(a)

Figure 3. Cont. 

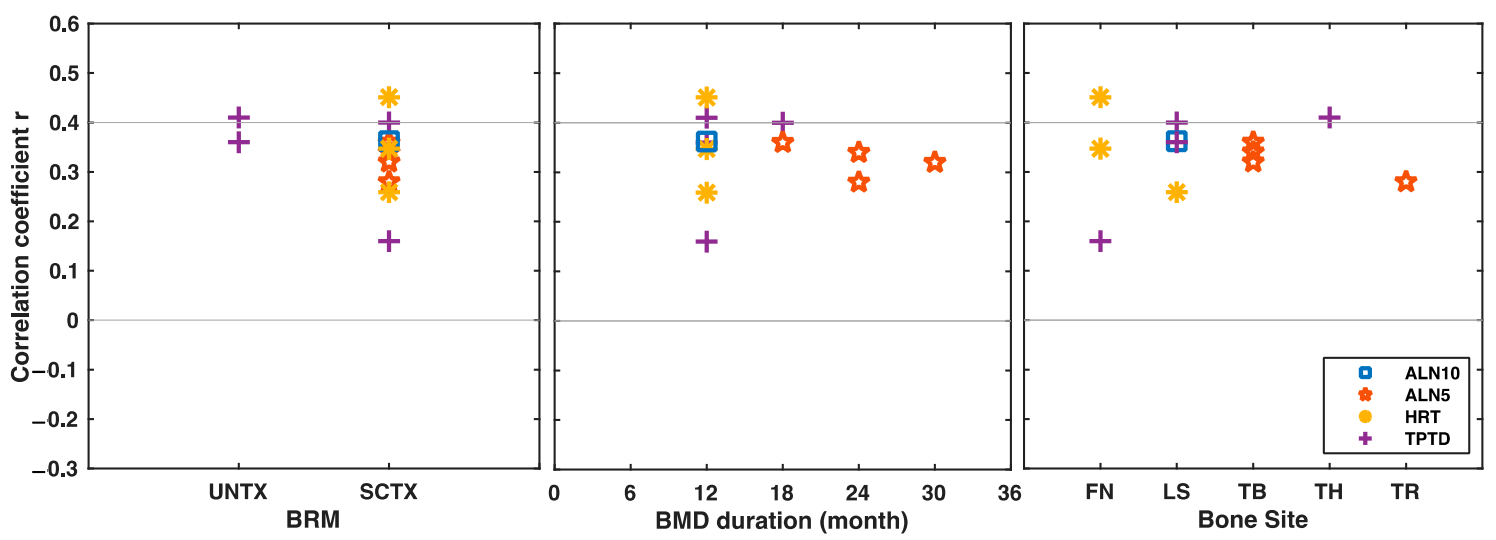

(b)

Figure 3. Significant correlations between baseline bone turnover markers (BTMs) and bone mineral density (BMD) changes at different bone sites under different drug interventions over time. (a) Correlations between baseline BFMs and BMD changes from baseline at different bone sites under different drug interventions over time. (b) Correlations between baseline BRMs and BMD changes from baseline under different drug interventions over time. BFM bone formation marker, BRM bone resorption marker, ALN alendronate, ALN5 5 mg/d ALN, ALN10 10 mg/d ALN, ALN10+HRT, combination of $10 \mathrm{mg} / \mathrm{d}$ ALN and HRT, HRT hormone replacement therapy, TPTD teriparatide, FN femoral neck, LS lumbar spine, TB total body, TH total hip, TR trochanter.
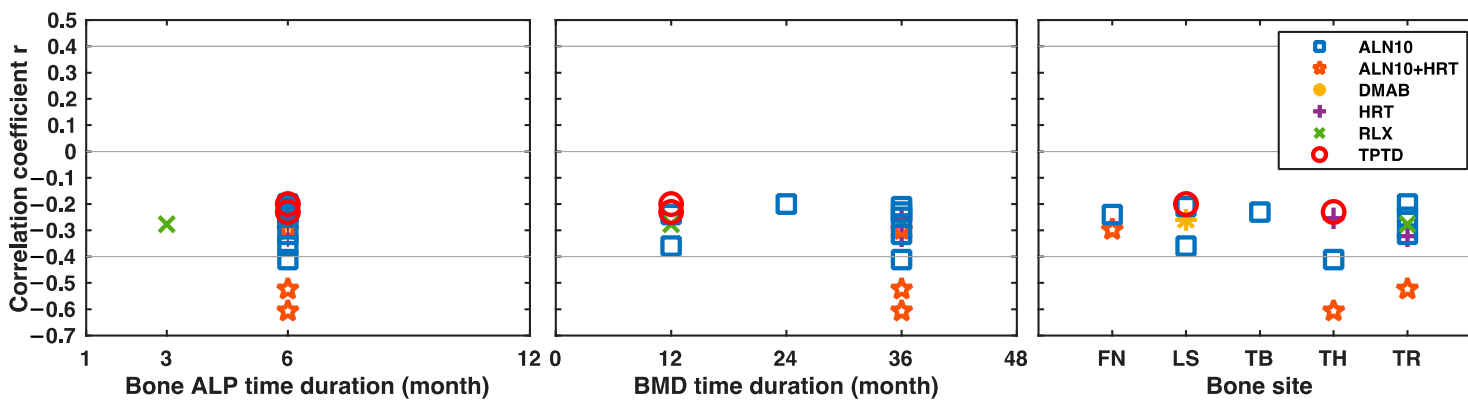

(a)
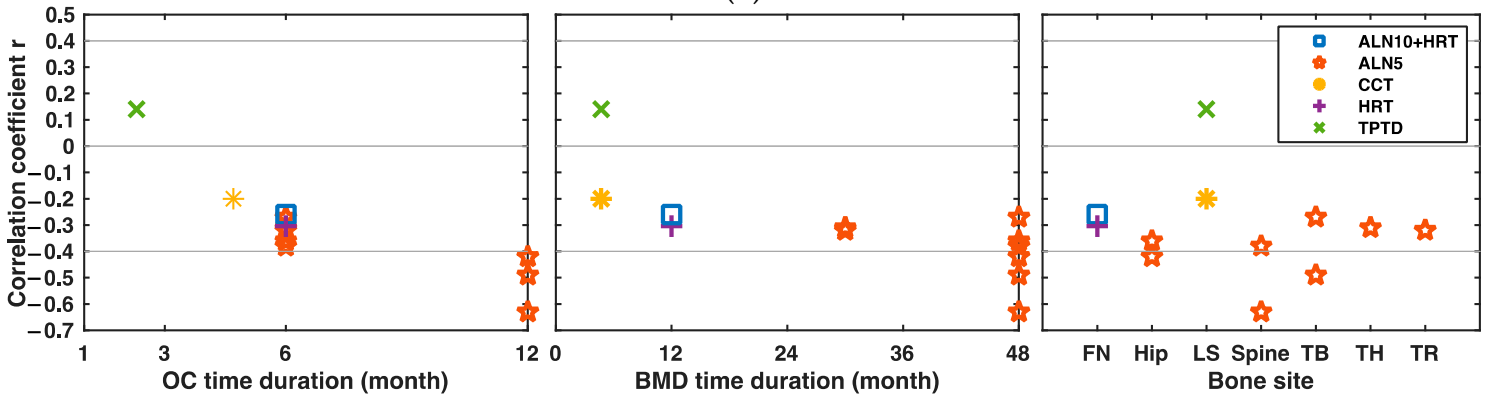

(b)
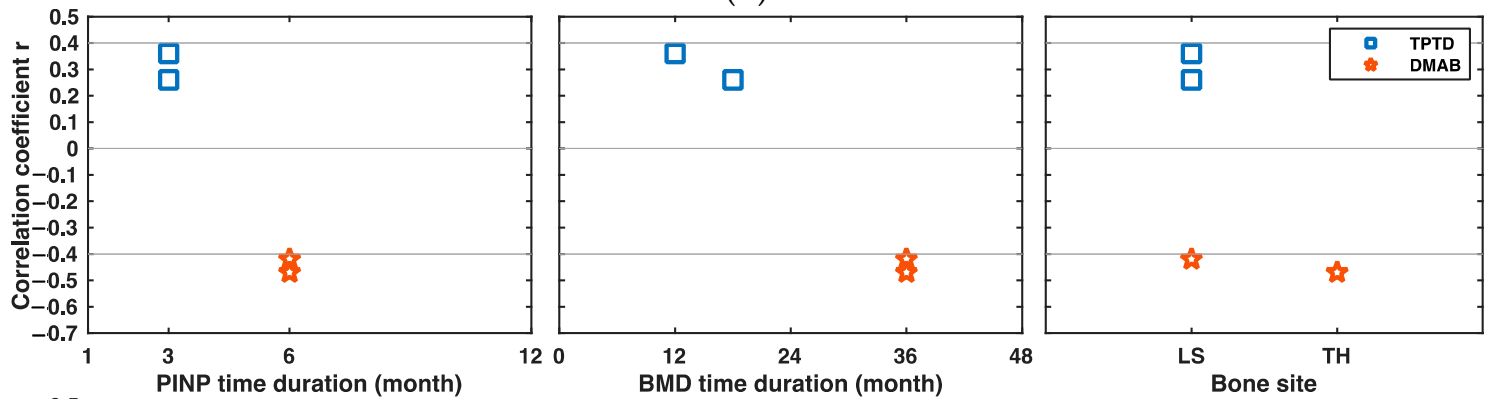

(c)

Figure 4. Cont. 

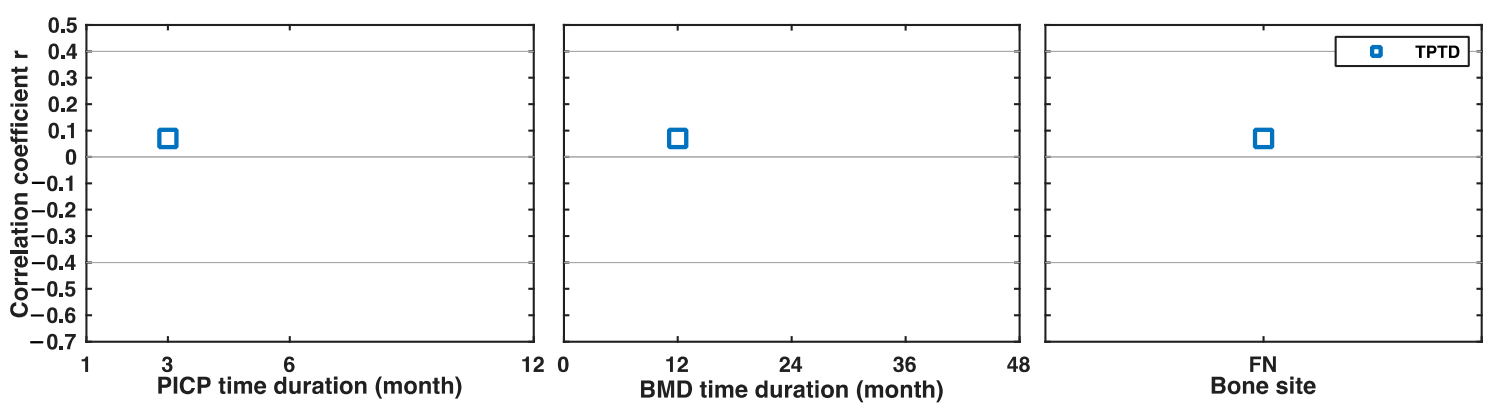

(d)

Figure 4. Significant correlations between the changes in BFMs and BMD at different bone sites under different drug interventions over time. (a) Correlations between the changes in bone ALP and BMD from baseline at different bone sites under different drug interventions over time. (b) Correlations between the changes in osteocalcin (OC) and BMD under different drug interventions over time. (c) Correlations between the changes in procollagen type I N propeptide (PINP) and BMD under different drug interventions over time. (d) Correlations between the changes in PICP and BMD under different drug interventions over time. ALN alendronate, ALN5 5 mg/d ALN, ALN10 10 mg/d ALN, ALN10+HRT, combination of $10 \mathrm{mg} / \mathrm{d}$ ALN and HRT, BFM bone formation marker, CCT calcitonin, DMAB denosumab, HRT hormone replacement therapy, RLX raloxifene, TPTD teriparatide, FN femoral neck, LS lumbar spine, TB total body, TH total hip, TR trochanter.
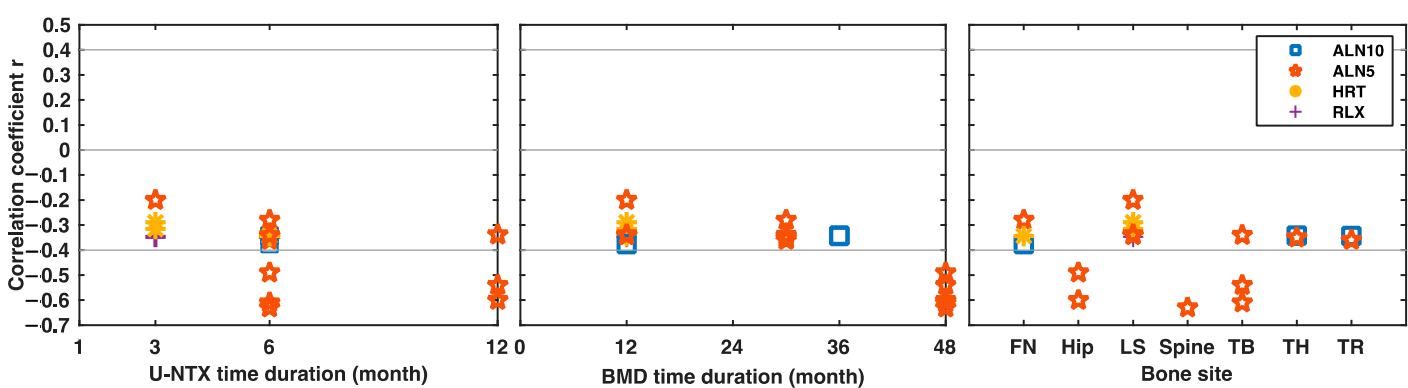

(a)
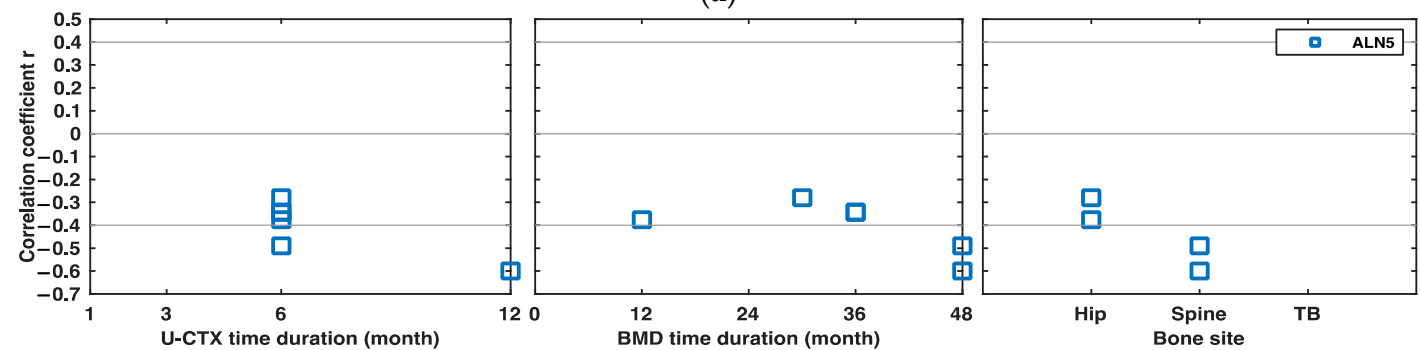

(b)
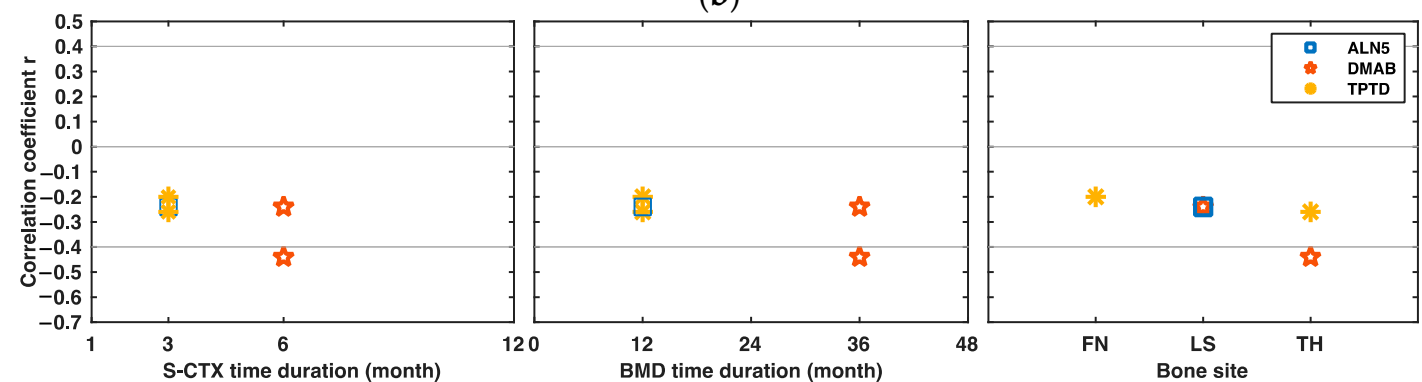

(c)

Figure 5. Cont. 

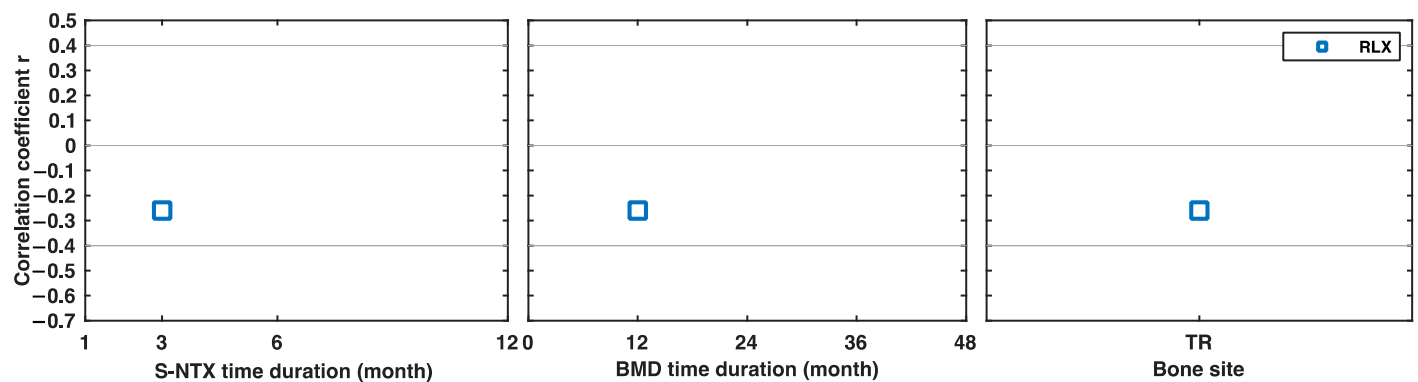

(d)

Figure 5. Significant correlations between the changes in BRMs and BMD at different bone sites under different drug interventions over time. (a) Correlations between the changes in urine N-terminal crosslinking telopeptide of type I collagen (U-NTX) and BMD from baseline at different bone sites under different drug interventions over time. (b) Correlations between the changes in U-CTX and BMD under different drug interventions over time. (c) Correlations between the changes in S-CTX and BMD under different drug interventions over time. (d) Correlations between the changes in S-NTX and BMD under different drug interventions over time. ALN alendronate, ALN5 5 mg/d ALN, ALN10 10 mg/d ALN, ALN10+HRT, combination of $10 \mathrm{mg} / \mathrm{d}$ ALN and HRT, BRM bone resorption marker, CTX serum C-terminal crosslinking telopeptide of type I collagen, DMAB denosumab, HRT hormone replacement therapy, RLX raloxifene, TPTD teriparatide, FN femoral neck, LS lumbar spine, S-CTX serum CTX, U-CTX urine CTX, TB total body, TH total hip, TR trochanter.

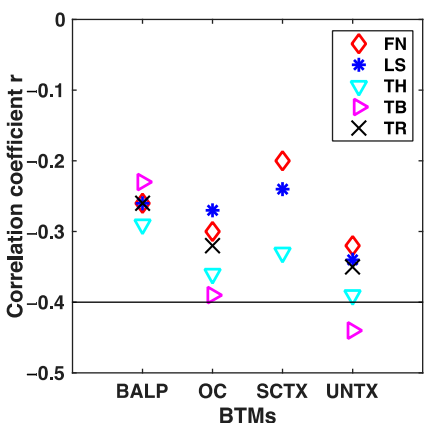

(a)

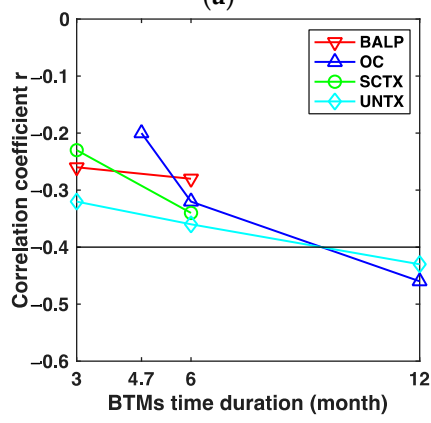

(c)

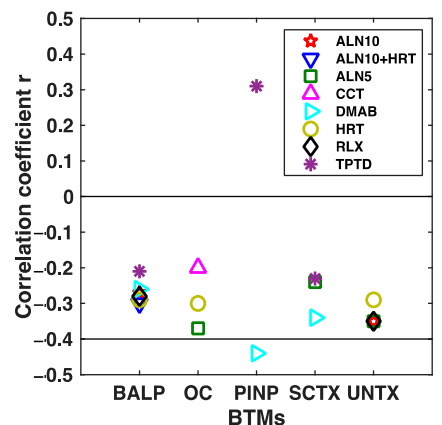

(b)

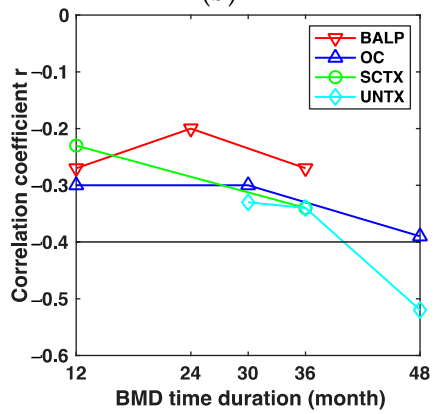

(d)

Figure 6. Assembled results of the subgroup analyses. (a) Assembled CORs between the changes in BTMs and BMD from baseline by group of bone sites. (b) Assembled CORs between the changes in BTMs and BMD from baseline by group of drug intervention. (c) Assembled CORs between the changes in BTMs and BMD from baseline by group of the time duration of BTMs measurements. (d) Assembled CORs between the changes in BTMs and BMD from baseline by group of the time duration of BMD measurements. ALN alendronate, ALN5 5 mg/d ALN, ALN10 10 mg/d ALN, ALN10+HRT, combination of $10 \mathrm{mg} / \mathrm{d}$ ALN and HRT, CCT calcitonin, COR summary correlation coefficient $r$, DMAB denosumab, HRT hormone replacement therapy, RLX raloxifene, TPTD teriparatide, FN femoral neck, LS lumbar spine, TB total body, TH total hip, TR trochanter. 
Table 1. Characteristics of the eligible studies.

\begin{tabular}{|c|c|c|c|c|c|c|c|c|c|c|}
\hline Study & Age & Sex & Sample Size & $\begin{array}{l}\text { Ethnicity } \\
\text { /Region }\end{array}$ & Disease & Study Design & Intervention & $\begin{array}{c}\text { Duration } \\
\text { (Years) }\end{array}$ & Supplementation & Reference \\
\hline Tsujimoto 2011 & $70(\geq 55)$ & $\mathrm{F} / \mathrm{M}$ & 193/14 & Japanese & PMW & RCTs & $20 \mu \mathrm{g} / \mathrm{d}$ TPTD; PBO & 1 & $\begin{array}{l}\text { All subjects received } 610 \mathrm{mg} \text { calcium and } 400 \\
\text { IU vitamin D supplementation daily }\end{array}$ & [12] \\
\hline Kim 2005 & $56.4 \pm 5.8$ & $\mathrm{~F}$ & 88 & Korean & PMO & Prospective study & $\begin{array}{c}0.625 \mathrm{mg} \mathrm{CEE}+ \\
(2.5-10 \mathrm{mg}) / \mathrm{d} \text { MPA }\end{array}$ & 1 & $\begin{array}{l}\text { All subjects also received } 500 \mathrm{mg} / \text { day of } \\
\text { elemental calcium and } 400 \mathrm{IU} \text { of vitamin D3. }\end{array}$ & [13] \\
\hline Chen 2005 & $69.0 \pm 6.9$ & F & 1085 & multi-center & PMO & $\mathrm{RCTs}$ & $20 \mu \mathrm{g} / \mathrm{d}$ TPTP; PBO & 1.75 & $\begin{array}{l}\text { Daily calcium ( } 1000 \mathrm{mg}) \text { and vitamin D } \\
(400-1200 \mathrm{IU}) \text { supplementation. }\end{array}$ & [14] \\
\hline Greenspan 2005 & $71 \pm 4$ & F & 93 & Boston & PMO & $\begin{array}{l}\text { Double-blinded } \\
\text { RCTs }\end{array}$ & $\begin{array}{l}10 \mathrm{mg} / \mathrm{d} \text { ALN; HRT; } \\
10 \mathrm{mg} / \mathrm{d} \text { ALN+HRT; } \\
\text { PBO }\end{array}$ & 3 & $\begin{array}{l}\text { All received daily multivitamin containing } \\
400 \text { IU per tablet so that their daily vitamin D } \\
\text { intake was } 400-800 \mathrm{IU}\end{array}$ & [15] \\
\hline Ravn 2003 & $45-59$ & F & 122 & $\begin{array}{l}\text { Denmark, } \\
\text { England, } \\
\text { America, Poland }\end{array}$ & PMW & Single-blinded RCTs & $\begin{array}{c}5 \mathrm{mg} / \mathrm{d} \mathrm{ALN} ; 2.5 \mathrm{mg} / \mathrm{d} \\
\text { ALN; PBO }\end{array}$ & 4 & NR & [16] \\
\hline Eastell 2011 & $69.0 \pm 6.9$ & F & 96 & International & PMO & $\mathrm{RCTs}$ & $\begin{array}{l}60 \mathrm{mg} /(6 \mathrm{months}) \\
\text { Denosumab; PBO }\end{array}$ & 3 & $\begin{array}{l}\text { Daily calcium intake }>1000 \mathrm{mg} \text {, patient with } \\
12-20 \mathrm{ng} / \mathrm{mL} \text {, take vitamin } \mathrm{D}>800 \mathrm{IU} / \mathrm{d} \\
\text { others vitamin } D \text { intake }>400 \mathrm{IU} / \mathrm{d}\end{array}$ & [17] \\
\hline Okabe 2004 & $57.2 \pm 5.9$ & F & 22 & Japanese & PMO & Prospective study & $\begin{array}{l}1 \mathrm{mg} / \mathrm{d} \text { estradiol }+50 \\
\mu \mathrm{g} / \mathrm{d} \text { norethisterone }\end{array}$ & 1 & $\mathrm{NR}$ & [18] \\
\hline Majima 2008 & $71.2 \pm 9.1$ & $\mathrm{~F}$ & 73 & Japanese & PMO & Prospective study & $60 \mathrm{mg} / \mathrm{d}$ RLX & 1 & NR & [19] \\
\hline Nenonen 2005 & $50-56$ & F & 75 & Finland & PMO & $\begin{array}{c}\text { Double-blinded } \\
\text { RCTs }\end{array}$ & $\begin{array}{c}5 \mathrm{mg} / \mathrm{d} \text { ALN; } 10 \mathrm{mg} / \mathrm{d} \\
\text { ALN; PBO }\end{array}$ & 1 & $\begin{array}{l}\text { All subjects took } 630 \mathrm{mg} \text { calcium carbonate } \\
\text { and } 400 \mathrm{IU} \text { vitamin D daily }\end{array}$ & [20] \\
\hline Greenspan 1998 & $69.7 \pm 4.4$ & $\mathrm{~F}$ & 60 & America & PMW & $\begin{array}{l}\text { Double-blinded } \\
\text { RCTs }\end{array}$ & $\begin{array}{l}5 \mathrm{mg} / \mathrm{d} \text { ALN + } 10 \\
\mathrm{mg} / \mathrm{d} \text { ALN; PBO }\end{array}$ & 2.5 & $\mathrm{Ca}+$ vitamin $\mathrm{D}$ & [21] \\
\hline Garnero 1999 & $64.0 \pm 7$ & F & 307 & France & PMO & $\begin{array}{l}\text { Double-blinded } \\
\text { RCTs }\end{array}$ & 10 mg/d ALN; PBO & 2 & $500 \mathrm{mg} / \mathrm{d}$ Ca tablet & [22] \\
\hline Watts 2001 & $45-84$ & F & 134 & Caucasian & PMO & Multicenter, RCTs & 10 mg/d ALN; PBO & $\geq 1$ & $500 \mathrm{mg} / \mathrm{d}$ calcium carbonate tablet & [23] \\
\hline Drake 2003 & $31-87$ & M & 120 & Caucasian $(97 \%)$ & OP & $\begin{array}{l}\text { Double-blinded } \\
\text { RCTs }\end{array}$ & 10 mg/d ALN; PBO; & 2 & $\begin{array}{l}500 \mathrm{mg} / \text { day elemental calcium, and vitamin D } \\
\text { (dose not report) }\end{array}$ & [24] \\
\hline Eastell 2003 & $69 \pm 7$ & $\mathrm{~F}$ & 358 & $\begin{array}{l}\text { European, } \\
\text { Australian, } \\
\text { north American }\end{array}$ & PMO & $\begin{array}{l}\text { Double-blinded } \\
\text { RCTs }\end{array}$ & 5 mg/d RIS; PBO & 3 & $\begin{array}{l}\text { All subjects received } 1000 \mathrm{mg} / \text { day elemental } \\
\text { calcium, and up to } 500 \mathrm{IU} \text { vitamin D if } \\
\text { baseline levels were low }\end{array}$ & [25] \\
\hline Iwamoto 2005 & $71.9 \pm 7.5$ & $\mathrm{~F}$ & 105 & Japanese & PMO & Prospective study & $5 \mathrm{mg} / \mathrm{d}$ ALN & 1 & $\begin{array}{l}\text { All the subjects were instructed to take at least } \\
800 \mathrm{mg} \text { calcium daily through intake of } \\
\text { calcium-rich foods. }\end{array}$ & [26] \\
\hline Lu 2017 & $69.0 \pm 7.1$ & $\mathrm{~F}$ & $109 / 11$ & Chinese & OP & Open label RCTs & $\begin{array}{l}200 \mathrm{IU} / \mathrm{d} \text { CCT; } 20 \mu \mathrm{g} / \mathrm{d} \\
\text { TPTD; PBO }\end{array}$ & 0.47 & $\begin{array}{l}500-650 \mathrm{mg} / \text { day elemental calcium and } 200 \text { to } \\
400 \mathrm{IU} / \text { day vitamin D supplementation }\end{array}$ & [27] \\
\hline Iikuni 2012 & $69.7 \pm 9.1$ & F & 2784 & Japanese & PMO & Prospective study & $60 \mathrm{mg} / \mathrm{d}$ RLX & 3 & NR & [28] \\
\hline Takada 2012 & $67.0 \pm 5.0$ & $\mathrm{~F}$ & 45 & Japanese & PMO & Prospective study & $60 \mathrm{mg} / \mathrm{d}$ RLX & 3 & NR & [29] \\
\hline Delmas 2000 & $53.1 \pm 3.5$ & $\mathrm{~F}$ & 569 & Denmark & PMO & RCTs & $\begin{array}{l}\text { HRT (17ß-estradiol); } \\
\text { PBO }\end{array}$ & 2 & $\begin{array}{l}\text { All women with calcium intake lower than } 1 \\
\mathrm{~g} / \mathrm{d} \text { take } 500 \mathrm{mg} / \mathrm{d} \text { calcium supplementation }\end{array}$ & [30] \\
\hline
\end{tabular}


Table 1. Cont.

\begin{tabular}{|c|c|c|c|c|c|c|c|c|c|c|}
\hline Study & Age & Sex & Sample Size & $\begin{array}{l}\text { Ethnicity } \\
\text { /Region }\end{array}$ & Disease & Study Design & Intervention & $\begin{array}{c}\text { Duration } \\
\text { (Years) }\end{array}$ & Supplementation & Reference \\
\hline Riis 1995 & $51.0 \pm 2.2$ & $\mathrm{~F}$ & 119 & Denmark & PMW & $\begin{array}{l}\text { Double-masked } \\
\text { RCTs }\end{array}$ & HRT; PBO & 2 & NR & [31] \\
\hline Chen 1996 & $52.3 \pm 0.7$ & $\mathrm{~F}$ & 36 & Japanese & PMO/Openia & Prospective study & $\begin{array}{c}0.625 \mathrm{mg} \text { CEE }+2.5 \\
\mathrm{mg} / \mathrm{d} \text { MPA }\end{array}$ & 1 & NR & [32] \\
\hline Zhan 1999 & $55.9 \pm 8.4$ & $\mathrm{~F}$ & 48 & Japanese & PMO & Prospective study & $\begin{array}{l}0.625 \mathrm{mg} \mathrm{CEE}+2.5 \\
\mathrm{mg} / \mathrm{d} \text { progesteron; } \\
1 \alpha \text {-vD; PBO }\end{array}$ & 3 & $\begin{array}{l}\text { Subjects in group HRT and PBO took } 2-3 \mathrm{~g} \\
\text { calcium, while } 1 \alpha-\mathrm{D} 3 \text { group took } 1 \mathrm{~g} / \mathrm{d}\end{array}$ & [33] \\
\hline
\end{tabular}

Abbreviations: ALN alendronate, ALN5 $5 \mathrm{mg} / \mathrm{d}$ alendronate, ALN10 $10 \mathrm{mg} / \mathrm{d}$ alendronate, CEE Conjugated estrogen, DMAB denosumab, F female, HRT Hormone replacement therapy,

IBAN ibandronate, M male, MPA medroxyprogesterone acetate, NR not reported, Openia osteopenia, PBO placebo, PMO postmenopausal osteoporosis, PMW postmenopausal women,

RCTs randomized controlled trials, RIS risedronate, TPTD teriparatide. 


\section{Discussion}

Two previous systematic reviews have been performed on the use of serum or baseline BTMs for monitoring the early response to osteoporosis treatment, especially in fracture prediction and patients' persistence/adherence to therapy [34,35]. The correlations between the BTMs and the BMD changes were also investigated, but the analyses on the correlations between the BTMs and the BMD changes were not incomplete $[34,35]$. It should also be noted that even though the correlations between BTMs and BMD changes have been studied in the last 20 years, the quantitative relation between are still not clearly established. In this review, we made a systematic analysis of the correlation between the BTMs and BMD changes based on all available data with the intention to evaluate the value of the BTMs in predicting long-term BMD changes and identify several promising biomarkers for further study on their clinical application. We revealed the correlation between the BTMs and BMD changes in terms of bone sites, intervention, time duration of the BTMs measurements, and time duration of the BMD measurements.

According to the results of the systematic review, the correlation of the baseline BTMs with BMD changes from baseline after drug intervention were all positively correlated, and the intensity of the correlation presented a big disparity as the bone sites, intervention, time duration of BTMs, and BMD measurements varied. For the BTMs after intervention, the changes in BTMs and BMD from baseline were positively correlated under antiresorptive therapy; under the anabolic therapy (i.e., teriparatide), the correlation between the changes in BTMs and BMD were not consistent in the direction; however, from the results of the systematic review, the correlation under anabolic therapy were all weak.

Based on the results of the systematic review, further subgroup analyses were performed to evaluate the promising BTMs that presented a meaningful correlation with the BMD changes. According to the results of the systematic review, several BTMs presented moderately strong correlation with the BMD changes under specific conditions, such as bone ALP, osteocalcin, PINP, urine NTX, and urine/serum CTX. The further subgroup analyses on their correlation with the BMD changes in terms of bone sites, intervention, time duration of BTMs measurements, and time duration of BMD measurements indicated that the correlation of the biomarkers of osteocalcin, PINP, and urine NTX with BMD changes under specific conditions were moderately strong and negative. Therefore, the three promising BTMs may play a role in evaluating the long-term BMD changes and therefore could be valuable in the prediction of the future fracture risk after drug intervention; however, they still need to be further studied for the clinical application. As for the other BTMs, they were not specific according to the subgroup analyses and therefore were excluded from the promising candidates.

Osteocalcin, the product of the osteoblasts, was thought to reflect the activity of the bone formation [36]. PINP, the product during the process of the collagen formation, was also the biomarker for the process of the bone formation [37]. Urine NTX, the product during the process of the collagen degradation, was thought to be the marker for the bone resorption process [38]. According to this study, the moderate correlations between the BMD changes and the three identified BTMs (i.e., osteocalcin, PINP, and urine NTX) suggest that the three biomarkers are valuable in predicting the future BMD changes. Furthermore, if the BMD changes could be quantitatively calculated by the identified biomarkers, the fracture risk could be better predicted with the early changes of the biomarkers, therefore providing the physicians with better references in evaluating the efficacy of the treatment. In addition, the three biomarkers could be used potentially in evaluating the fracture risk not only in osteoporosis patients but in the patients whose diseases were associated with the imbalance in bone remodeling, such as Paget's disease, diabetes, and so on.

Although we tried to search for all possible data that investigated the relationship between BTMs and BMD in patients treated for osteoporosis, some useful information would inevitably be missing. Furthermore, due to many restrictions, such as different time duration of the measurements of BMD and BTMs, different anti-osteoporosis interventions, different bone sites, and different BTMs, the final number of eligible studies allocated to each subgroup was limited to a range from 1 to 6 , which affected the accuracy, interpretation, and extension of our conclusions. We excluded correlation data in the 
placebo group because they were not statistically significant. Some significant correlation data were also excluded from this systematic review because they were initially calculated for total patients from the intervention group and placebo group rather than for patients merely from the intervention group; therefore, they were not worthy of in-depth analyses. Additionally, the eligible studies assessed as high risk or unclear risk were involved in this systematic review and meta-analysis, and the validity of our conclusions may be affected.

\section{Conclusions}

Overall, by using the systematic review and meta-analysis, we found that PINP at baseline or changes from baseline, osteocalcin changes from baseline, and urine NTX changes from baseline were moderately correlated with BMD changes after drug intervention, showing the potential value of these biomarkers in evaluating the long-term BMD changes after drug intervention. As for the clinical application of these BTMs, their prediction of fracture risk after drug intervention combined with BMD changes needs to be further studied.

Supplementary Materials: The following are available online at http://www.mdpi.com/2076-3417/10/3/832/s1, Supporting information are provided as supplementary materials, including ESM_1, ESM_2, ESM_3, and ESM_4.

Author Contributions: Conceptualization, L.H. and L.M.; methodology, L.H. and D.L.; software, L.H. and M.W.; validation, L.H., D.L. and L.M.; formal analysis, L.H. and D.L.; investigation, L.H., D.L. and F.W.; resources, L.H. and Y.C.; data curation, L.H. and D.L.; writing—original draft preparation, L.H. and D.L.; writing-review and editing, L.H., D.L., F.W. and M.Q.W.; visualization, L.H.; supervision, L.H., D.L., F.W. and L.M.; project administration, L.H., D.L. and L.M.; funding acquisition, L.M. All authors have read and agreed to the published version of the manuscript.

Funding: This research was funded by the Special Foundation for the Development of Strategic Emerging Industries of Shenzhen, grant number JSGG20160428181846047, and Science and Technology Planning Project of Shenzhen Municipality, grant number GJHS20170314165540863.

Acknowledgments: We thank Tsinghua University for its generous support of necessary software and access to databases. We are thankful to Chaowen Xue, Shihe Wu, and Jieying Li for their assistance with the writing of this article.

Conflicts of Interest: The authors declare no conflict of interest. The funders had no role in the design of the study; in the collection, analyses, or interpretation of data; in the writing of the manuscript, or in the decision to publish the results.

\section{References}

1. Looker, A.C.; Wahner, H.W.; Dunn, W.L.; Calvo, M.S.; Harris, T.B.; Heyse, S.P.; Johnston, C.C., Jr.; Lindsay, R. Updated Data on Proximal Femur Bone Mineral Levels of US Adults. Osteoporos. Int. 1998, 8, 468-490. [CrossRef]

2. Black, D.M.; Rosen, C.J. Clinical Practice. Postmenopausal Osteoporosis. N. Engl. J. Med. 2016, 374, $254-262$. [CrossRef] [PubMed]

3. Faulkner, K.G. Bone matters: Are density increases necessary to reduce fracture risk? J. Bone Miner. Res. 2000, 15, 183-187. [CrossRef] [PubMed]

4. Vasikaran, S.D. Utility of biochemical markers of bone turnover and bone mineral density in management of osteoporosis. Crit. Rev. Clin. Lab. Sci. 2008, 45, 221-258. [CrossRef] [PubMed]

5. Delmas, P.D.; Eastell, R.; Garnero, P.; Seibel, M.J.; Stepan, J.; Committee of Scientific Advisors of the International Osteoporosis Foundation. The Use of Biochemical Markers of Bone Turnover in Osteoporosis. Osteoporos. Int. 2000, 11, S2-S17. [CrossRef] [PubMed]

6. Vilaca, T.; Gossiel, F.; Eastell, R. Bone Turnover Markers: Use in Fracture Prediction. J. Clin. Densitom. 2017, 20, 346-352. [CrossRef]

7. Moher, D.; Shamseer, L.; Clarke, M.; Ghersi, D.; Liberati, A.; Petticrew, M.; Shekelle, P.; Stewart, L.A. Preferred reporting items for systematic review and meta-analysis protocols (PRISMA-P) 2015 statement. Syst. Rev. 2015, 4, 1. [CrossRef] 
8. Higgins, J.P.T.; Altman, D.G.; Gøtzsche, P.C.; Jüni, P.; Moher, D.; Oxman, A.D.; Savović, J.; Schulz, K.F.; Weeks, L.; Sterne, J.A.C. The Cochrane Collaboration's tool for assessing risk of bias in randomised trials. BMJ 2011, 343, d5928. [CrossRef]

9. Sterne, J.A.C.; Hernán, M.A.; Reeves, B.C.; Savović, J.; Berkman, N.D.; Viswanathan, M.; Henry, D.; Altman, D.G.; Ansari, M.T.; Boutron, I.; et al. ROBINS-I: A tool for assessing risk of bias in non-randomised studies of interventions. BMJ 2016, 355, i4919. [CrossRef]

10. Borenstein, M.; Hedges, L.V.; Higgins, J.P.T.; Rothstein, H.R. Introduction to Meta-Analysis; John Wiley \& Sons: Chichester, UK, 2009; pp. 41-43.

11. Higgins, J.P.T.; Thompson, S.G.; Deeks, J.J.; Altman, D.G. Measuring inconsistency in meta-analyses. BMJ 2003, 327, 557-560. [CrossRef]

12. Tsujimoto, M.; Chen, P.; Miyauchi, A.; Sowa, H.; Krege, J. PINP as an aid for monitoring patients treated with teriparatide. Bone 2011, 48, 798-803. [CrossRef] [PubMed]

13. Kim, S.W.; Park, D.J.; Park, K.S.; Kim, S.Y.; Cho, B.Y.; Lee, H.K.; Shin, C.S. Early changes in biochemical markers of bone turnover predict bone mineral density response to antiresorptive therapy in Korean postmenopausal women with osteoporosis. Endocr. J. 2005, 52, 667-674. [CrossRef] [PubMed]

14. Chen, P.; Satterwhite, J.; Licata, A.; Lewiecki, E.; Sipos, A.; Misurski, D.; Wagman, R. Early changes in biochemical markers of bone formation predict BMD response to teriparatide in postmenopausal women with osteoporosis. J. Bone Miner. Res. 2005, 20, 962-970. [CrossRef] [PubMed]

15. Greenspan, S.; Resnick, N.; Parker, R. Early changes in biochemical markers of bone turnover are associated with long-term changes in bone mineral density in elderly women on alendronate, hormone replacement therapy, or combination therapy: A three-year, double-blind, placebo-controlled, randomized clinical trial. J. Clin. Endocrinol. Metab. 2005, 90, 2762-2767. [PubMed]

16. Ravn, P.; Thompson, D.E.; Ross, P.D.; Christiansen, C. Biochemical markers for prediction of 4-year response in bone mass during bisphosphonate treatment for prevention of postmenopausal osteoporosis. Bone 2003, 33, 150-158. [CrossRef]

17. Eastell, R.; Christiansen, C.; Grauer, A.; Kutilek, S.; Libanati, C.; McClung, M.; Reid, I.; Resch, H.; Siris, E.; Uebelhart, D.; et al. Effects of denosumab on bone turnover markers in postmenopausal osteoporosis. J. Bone Miner. Res. 2011, 26, 530-537. [CrossRef] [PubMed]

18. Okabe, R.; Inaba, M.; Nakatsuka, K.; Miki, T.; Naka, H.; Moriguchi, A.; Nishizawa, Y. Significance of serum CrossLaps as a predictor of changes in bone mineral density during estrogen replacement therapy; comparison with serum carboxyterminal telopeptide of type I collagen and urinary deoxypyridinoline. J. Bone Miner. Metab. 2004, 22, 127-131. [CrossRef]

19. Majima, T.; Shimatsu, A.; Satoh, N.; Komatsu, Y.; Fukao, A.; Ninomiya, K.; Matsumura, T.; Nakao, K. Three-month changes in bone turnover markers and bone mineral density response to raloxifene in Japanese postmenopausal women with osteoporosis. J. Bone Miner. Metab. 2008, 26, 178-184. [CrossRef]

20. Nenonen, A.; Cheng, S.; Ivaska, K.K.; Alatalo, S.L.; Lehtimäki, T.; Schmidt-Gayk, H.; Uusi-Rasi, K.; Heinonen, A.; Kannus, P.; Sievänen, H.; et al. Serum TRACP $5 b$ is a useful marker for monitoring alendronate treatment: Comparison with other markers of bone turnover. J. Bone Miner. Res. 2005, 20, 1804-1812. [CrossRef]

21. Greenspan, S.; Parker, R.; Ferguson, L.; Rosen, H.; Maitland-Ramsey, L.; Karpf, D. Early changes in biochemical markers of bone turnover predict the long-term response to alendronate therapy in representative elderly women: A randomized clinical trial. J. Bone Miner. Res. 1998, 13, 1431-1438. [CrossRef]

22. Garnero, P.; Darte, C.; Delmas, P. A msodel to monitor the efficacy of alendronate treatment in women with osteoporosis using a biochemical marker of bone turnover. Bone 1999, 24, 603-609. [CrossRef]

23. Watts, N.; Jenkins, D.; Visor, J.; Casal, D.; Geusens, P. Comparison of bone and total alkaline phosphatase and bone mineral density in postmenopausal osteoporotic women treated with alendronate. Osteoporos. Int. 2001, 12, 279-288. [CrossRef] [PubMed]

24. Drake, W.M.; Kendler, D.L.; Rosen, C.J.; Orwoll, E.S. An investigation of the predictors of bone mineral density and response to therapy with alendronate in osteoporotic men. J. Clin. Endocrinol. Metab. 2003, 88, 5759-5765. [CrossRef]

25. Eastell, R.; Barton, I.; Hannon, R.; Chines, A.; Garnero, P.; Delmas, P. Relationship of early changes in bone resorption to the reduction in fracture risk with risedronate. J. Bone Miner. Res. 2003, 18, 1051-1056. [CrossRef] [PubMed] 
26. Iwamoto, J.; Takeda, T.; Sato, Y.; Uzawa, M. Early changes in urinary cross-linked N-terminal telopeptides of type I collagen level correlate with 1-year response of lumbar bone mineral density to alendronate in postmenopausal Japanese women with osteoporosis. J. Bone Miner. Metab. 2005, 23, 238-242. [CrossRef] [PubMed]

27. Lu, C.; Chen, Y.; Zhang, B.; Chen, Y.; Bai, F.; Chen, D. Response to teriparatide in Chinese patients with established osteoporosis: Osteocalcin and lumbar spine bone-mineral density changes from teriparatide Phase III study. Clin. Interv. Aging 2017, 12, 1717-1723. [CrossRef] [PubMed]

28. Iikuni, N.; Hamaya, E.; Nihojima, S.; Yokoyama, S.; Goto, W.; Taketsuna, M.; Miyauchi, A.; Sowa, H. Safety and effectiveness profile of raloxifene in long-term, prospective, postmarketing surveillance. J. Bone Miner. Metab. 2012, 30, 674-682. [CrossRef]

29. Takada, J.; Iba, K.; Yoshizaki, T.; Yamashita, T. Correlation between a bone resorption marker and structural geometry of the proximal femur in osteoporotic women treated with raloxifene. J. Orthop. Surg. (Hong Kong) 2012, 20, 209-213. [CrossRef]

30. Delmas, P.D.; Hardy, P.; Garnero, P.; Dain, M. Monitoring individual response to hormone replacement therapy with bone markers. Bone 2000, 26, 553-560. [CrossRef]

31. Riis, B.; Overgaard, K.; Christiansen, C. Biochemical markers of bone turnover to monitor the bone response to postmenopausal hormone replacement therapy. Osteoporos. Int. 1995, 5, 276-280. [CrossRef]

32. Chen, J.T.; Hosoda, K.; Hasumi, K.; Ogata, E.; Shiraki, M. Serum N-terminal osteocalcin is a good indicator for estimating responders to hormone replacement therapy in postmenopausal women. J. Bone Miner. Res. 1996, 11, 1784-1792. [CrossRef] [PubMed]

33. Zhan, Z.W.; Yamamoto, I.; Morita, R.; Miura, H. Urinary pyridinoline and deoxypyridinoline as bone metabolic markers in predicting therapeutic effects of estrogen and alfacalcidol in women with osteoporosis. J. Bone Miner. Metab. 1999, 17, 113-118. [CrossRef] [PubMed]

34. Funck-Brentano, T.; Biver, E.; Chopin, F.; Bouvard, B.; Coiffier, G.; Souberbielle, J.-C.; Garnero, P.; Roux, C. Clinical Utility of Serum Bone Turnover Markers in Postmenopausal Osteoporosis Therapy Monitoring: A Systematic Review. Semin. Arthritis Rheum. 2011, 41, 157-169. [CrossRef] [PubMed]

35. Biver, E.; Chopin, F.; Coiffier, G.; Brentano, T.F.; Bouvard, B.; Garnero, P.; Cortet, B. Bone turnover markers for osteoporotic status assessment? A systematic review of their diagnosis value at baseline in osteoporosis. Jt. Bone Spine 2012, 79, 20-25. [CrossRef] [PubMed]

36. Lian, J.B.; Gundberg, C.M. Osteocalcin. Biochemical considerations and clinical applications. Clin. Orthop. Relat. Res. 1988, 226, 267-291.

37. Linkhart, S.G.; Linkhart, T.A.; Taylor, A.K.; Wergedal, J.E.; Bettica, P.; Baylink, D.J. Synthetic peptide-based immunoassay for amino-terminal propeptide of type I procollagen: Application for evaluation of bone formation. Clin. Chem. 1993, 39, 2254. [CrossRef]

38. Hanson, D.A.; Weis, M.A.E.; Bollen, A.-M.; Maslan, S.L.; Singer, F.R.; Eyre, D.R. A specific immunoassay for monitoring human bone resorption: Quantitation of type I collagen cross-linked N-telopeptides in urine. J. Bone Miner. Res. 1992, 7, 1251-1258. [CrossRef]

(C) 2020 by the authors. Licensee MDPI, Basel, Switzerland. This article is an open access article distributed under the terms and conditions of the Creative Commons Attribution (CC BY) license (http://creativecommons.org/licenses/by/4.0/). 